\title{
Non-coding antisense transcription detected by conventional and single-stranded cDNA microarray Johan Vallon-Christersson ${ }^{1}$, Johan Staaf ${ }^{1}$, Anders Kvist ${ }^{2}$, Patrik Medstrand ${ }^{2}$, Åke Borg ${ }^{1,3}$ and Carlos Rovira*1,3
}

\author{
Address: ${ }^{1}$ Department of Oncology, Institute of Clinical Sciences, and SWEGENE DNA microarray resource center, Lund University, Barngatan 2:1, \\ SE-221 85 Lund, Sweden, ${ }^{2}$ Genomics and Bioinformatics, Department of Experimental Medical Science, BMC C13, SE-221 84 Lund, Sweden and \\ ${ }^{3}$ Lund Stem Cell Centre, University of Lund, BMC C13 SE-221 84 Lund, Sweden \\ Email: Johan Vallon-Christersson - johan.vallon-christersson@med.lu.se; Johan Staaf - johan.staaf@med.lu.se; \\ Anders Kvist - anders.kvist@med.lu.se; Patrik Medstrand - patrik.medstrand@med.lu.se; Åke Borg - ake.borg@med.lu.se; \\ Carlos Rovira* - carlos.rovira@med.lu.se \\ * Corresponding author
}

Published: 29 August 2007

BMC Genomics 2007, 8:295 doi:10.1/86/147|-2164-8-295
Received: 5 March 2007

Accepted: 29 August 2007

This article is available from: http://www.biomedcentral.com/I47I-2/64/8/295

(C) 2007 Vallon-Christersson et al; licensee BioMed Central Ltd.

This is an Open Access article distributed under the terms of the Creative Commons Attribution License (http://creativecommons.org/licenses/by/2.0), which permits unrestricted use, distribution, and reproduction in any medium, provided the original work is properly cited.

\begin{abstract}
Background: Recent studies revealed that many mammalian protein-coding genes also transcribe their complementary strands. This phenomenon raises questions regarding the validity of data obtained from double-stranded cDNA microarrays since hybridization to both strands may occur. Here, we wanted to analyze experimentally the incidence of antisense transcription in human cells and to estimate their influence on protein coding expression patterns obtained by double-stranded microarrays. Therefore, we profiled transcription of sense and antisense independently by using strand-specific cDNA microarrays.
\end{abstract}

Results: Up to $88 \%$ of expressed protein coding loci displayed concurrent expression from the complementary strand. Antisense transcription is cell specific and showed a strong tendency to be positively correlated to the expression of the sense counterparts. Even if their expression is widespread, detected antisense signals seem to have a limited distorting effect on sense profiles obtained with double-stranded probes.

Conclusion: Antisense transcription in humans can be far more common than previously estimated. However, it has limited influence on expression profiles obtained with conventional cDNA probes. This can be explained by a biological phenomena and a bias of the technique: a) a co-ordinate sense and antisense expression variation and b) a bias for sense-hybridization to occur with more efficiency, presumably due to variable exonic overlap between antisense transcripts.

\section{Background}

Non-coding RNAs have recently been reported as more common, more diverse, and accredited more important functions than previously anticipated [1-3]. Among the most abundant non-coding transcripts, there is a group called natural antisense transcripts (NATs) that carries regions of perfect complementarity to protein coding (sense) RNAs [4-7]. In silico studies of available transcript sequence data have found that up to $24 \%$ of human protein coding loci also encode cis-NATs $[8,9]$. However, antisense transcripts tend to be poly(A) negative and nuclear localized [10]. If this is true, the abundance of 
NATs (cis and trans) may be higher yet, since nuclear nonpolyadenylated transcripts are underrepresented in transcript sequence databases.

This fact may have important implications for researchers, not only because of their potential biological function but they may also turn out to be influential on the interpretation of large experimental data sets. For instance, the cDNA microarray technique has been used in genomewide expression studies to address basic questions about gene function and in the pursuit of a more precise molecular classification of tumors. In this case, the ability to monitor the expression of thousands of genes simultaneously has allowed the identification of disease-specific subsets of genes useful to improve diagnosis and disease management [11]. The majority of the more than 90.000 microarray expression profiles released through NCBI was obtained with double stranded cDNA capture probes and is assumed to reflect the pure expression of the sense transcripts used as templates for cDNA synthesis. However, the widespread expression of natural antisense transcripts (NATs) invalidates this assumption since double-stranded probes will show the combined expression of both the intended sense target and any NAT with complementary sequence $[12,13]$. Still, for nine out of ten cases, signals from double-stranded cDNA probes correlates with those obtained from sense specific oligonucleotide platforms [14]. Based on these observations, we reasoned that antisense transcripts are either not efficiently detected by conventional cDNA capture probes or that important information must be hidden behind this paradox.

Therefore, we modeled a typical cDNA microarray tumorclassification analysis and compared the results from conventional double-stranded cDNA capture probes with single stranded cDNA capture probes capable of monitoring opposite strands of each cDNA independently. We detected a number of antisense signals that exceed by far the number of known antisense transcripts. The detected signals showed a clear cell specific expression pattern with a common core group of antisenses expressed in all analyzed materials. Moreover, antisense transcripts displayed a prevalent tendency to be positively correlated with the expression of their corresponding sense counterparts. This confirms the idea that a large part of the data obtained from conventional double-stranded cDNA microarrays are in fact compounded signals product of both sense and antisense hybridization. Yet, detection of antisense transcription by conventional double-stranded cDNA microarrays does not strongly distort the relationship between expression profiles of the analyzed samples compared with those obtained from pure sense signals. This is most likely due to the observed coordinate regulation of senses and antisenses and a more efficient hybridization of sense strands because a different exon structure of antisense transcripts and the sense transcripts used for cDNA synthesis.

\section{Results and discussion Production of single-stranded microarrays}

We generated strand specific cDNA probes in situ after covalently binding $\mathrm{NH}_{2}$-modified cDNA inserts onto crosslinked N-hydroxysuccinamide slides in a strand specific manner. Specific binding of 5' DNA ends serves two different but additive purposes. First, 5 ' end-specific binding provide protection against in situ enzymatic attack of highly processive 5'-3' exonucleases; unbound strands could then be exposed to enzymatic degradation. Second, only 5'-end modified strands will be covalently bound, rendering non-modified strands vulnerable to easy removal by heat denaturation. We found that the most reliable method for processing double stranded cDNAs into single stranded capture probes was the sequential application of both approaches. The procedure is schematically depicted in Figure 1a. To validate the method, microarrays containing single-stranded sense and antisense probes and double-stranded probes (PCR products $\mathrm{NH}_{2}$-modifed at both 5 'ends that remain double-stranded after processing) were generated from a $1 \mathrm{~kb}$ fragment containing the $\beta$-lactamase gene. Hybridizations were performed with equimolar amounts of Cy3- or Cy5- directlabelled sense and antisense $\beta$-lactamase transcripts (Figure $1 \mathrm{~b}$ ). Sense probes showed strong signal from Cy3 labelled sense cDNA (532 nm wavelength) and signal equivalent to background level in the Cy5 channel ( 635 $\mathrm{nm}$ wavelength). Contrary, antisense probes detected strong signal from Cy5-labeled antisense cDNA while Cy3 signal remained equivalent to background (Figure 1c). We conclude that our method can produce selective single stranded DNA capture probes from double-stranded PCR products in situ with an efficacy and specificity sufficient to eliminate detectable levels of complementary strand, thus producing a selective array of strand-specific capture probes.

\section{Strand-specific cDNA microarrays}

Following this test, we prepared strand-specific sense and antisense cDNA probes, and double-stranded probes, from 960 randomly selected full-length cDNAs from the MGC clone collection. Both strand specifically $5^{\prime} \mathrm{NH}_{2}-$ modified PCR products for sense and antisense probe generation and $\mathrm{NH}_{2}$-modified products at both $5^{\prime}$ ends were printed on the same surface. In the following, sense probes are termed $\mathrm{C}$ for coding and antisense probes $\mathrm{N}$ for non-coding. Double-stranded probes are termed CN. To verify the specificity of our cDNA capture probes, we hybridized the arrays with Cy3 or Cy5 labeled universal primers used to amplify all cDNA inserts (see Methods). Data from the test hybridization shows that $\mathrm{CN}$ probes produce $\log _{2}$ ratio intensities centered on 0 , demonstrat- 


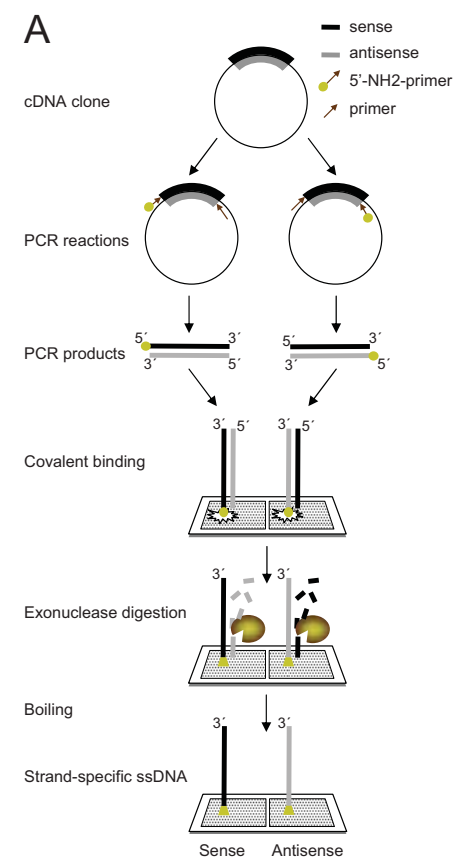

B

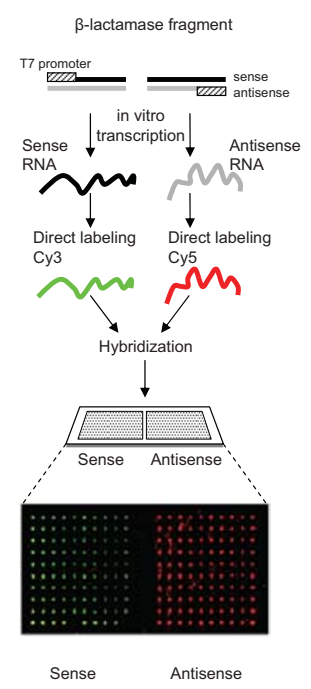

C

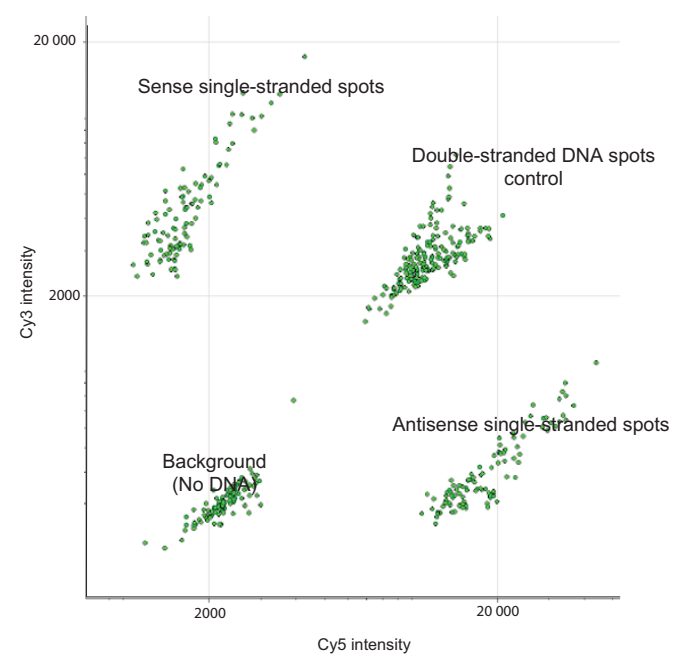

Figure I

In situ single stranded cDNA microarray production method (a) Strand-specific end modifications (amino-linkers) are incorporated into DNA by two parallel PCR reactions. After clean-up, the PCR product for each end-modified strand is printed separately onto the same microarray glass slide. The amino terminal groups are further coupled to the glass. The probes are digested with 5'-3' T7 gene 6 exonuclease and then immersed in boiling water. As a result of this treatment, only end-modifed strands remain attached to the surface. (b) Hybridization of labelled in vitro transcribed RNA from the $\beta$-lactamase gene with $\beta$-lactamase single-stranded sense and antisense DNA capture probes. Control spots containing ds-DNA probes or amino-modified PCR primers alone were also included on the array (not shown). Both probes and controls were spotted in $10 \times 10$ replicates. (c) Scatter plot showing the distribution of raw median pixel signal intensities from the hybridization performed in (b). Signals from all replicates are clearly discriminated according to the strand from which they originated (sense or antisense). Control spots for background intensities (printing buffer, PCR and amplification primers) demonstrate the specificity of the single stranded probes.

ing that they captured both labeled targets. Conversely, strand specific $\mathrm{C}$ and $\mathrm{N}$ probes produced $\log _{2}$ intensity ratios centered approximately on 5 and -5 respectively (Figure 2a). Figure $2 \mathrm{~b}$ show $\log _{2}$ ratios for $\mathrm{C}, \mathrm{N}$, and $\mathrm{CN}$ probe for each cDNA clone sorted on ascending basis for respective $\mathrm{CN}$ probes. With very few exceptions, each probe set consistently produced strand specific probes equally well across all cDNAs.

\section{Antisense detection of $N$ probes hybridized with total RNAs}

Next, we modeled an experimental design typically used for tumor classification studies. We performed hybridizations using direct-labeled randomly primed total RNA extracted from eight breast-cancer cell lines and one derived from normal breast epithelium against Universal Human Reference RNA as a common reference following standard protocols (see Methods). To control for even processing into strand-specific probes we printed internal $\beta$-lactamase DNA control spots in each block and included $\beta$-lactamase spike-in sense and antisense control targets in either samples or reference. Their hybridization signals confirmed that detected $\mathrm{N}$ signals reflect hybridization to the $\mathrm{N}$ probe over the entire array (Figure $2 \mathrm{c}$ ).

We initially analyzed the detection capacity of $\mathrm{N}$ probes. We applied a stringent filter criterion including signals with signal-to-noise (SNR) ratios above 10. Across all nine hybridizations, we detected $776 \mathrm{~N}$ signals in the cell lines and $885 \mathrm{~N}$ signals in the reference, out of the set of 960 probes (Table 1). We filtered for non-specific crosshybridization with repetitive elements in the probe sequence [19], extended self-complementarity between the $\mathrm{C}$ and $\mathrm{N}$ probes, and $\mathrm{C}$ and $\mathrm{N}$ probes with sequence 


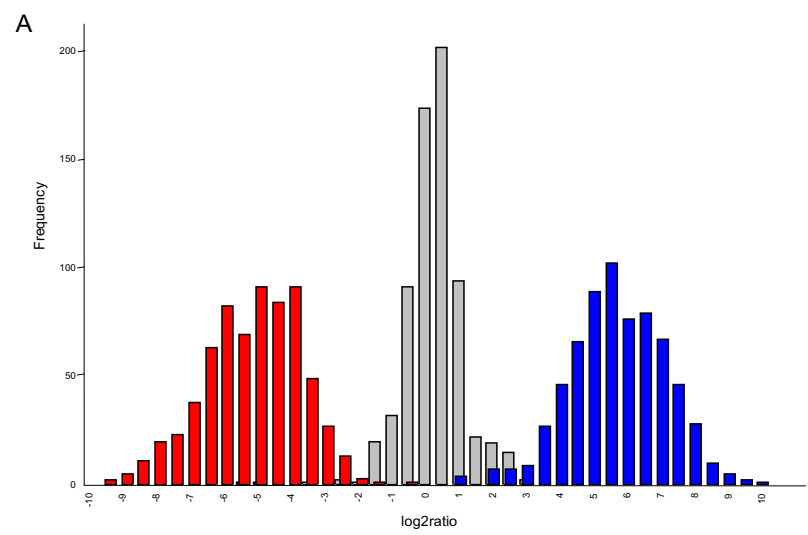

B
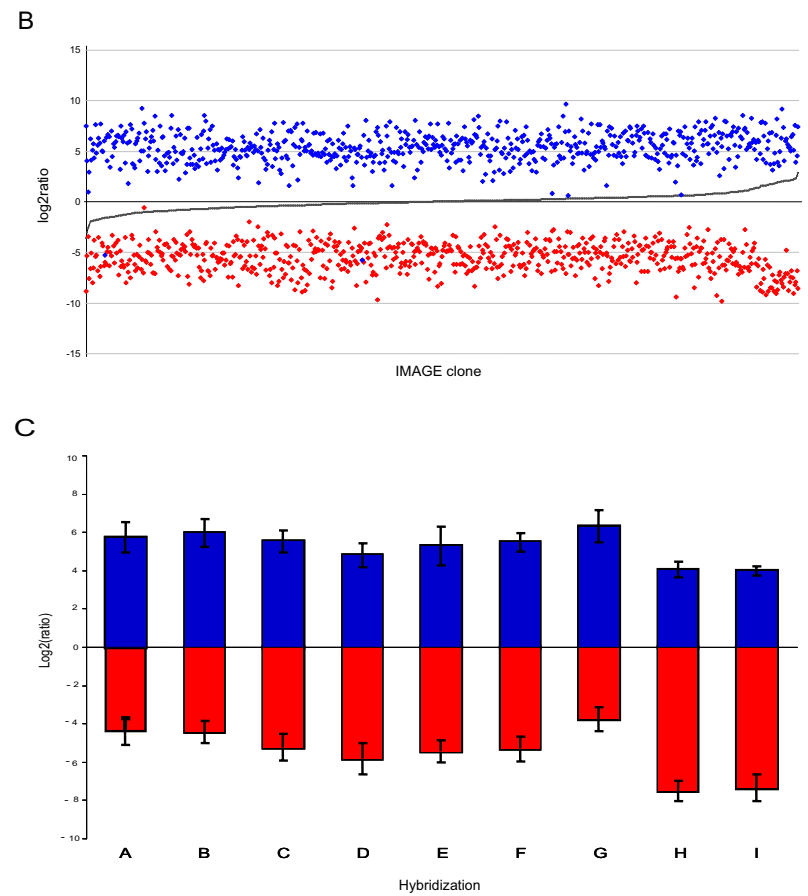

\section{Figure 2}

Strand specificity of in situ produced sense/antisense cDNA microarray features. (a) Histogram showing the distribution of $\log _{2}$ ratios after hybridization to single stranded $\mathrm{C}$ (blue), $\mathrm{N}$ (red), and double stranded CN (gray) capture probes with labelled Cy3- MI 3 forward and Cy5 - reverse sequencing primers (The $\log _{2}$ ratios for $\mathrm{C}$ and $\mathrm{N}$ probes from cDNA clones of plate IRAT3 were centered around -5 and 5 respectively, as expected since their cloning sites were reversed compared to the other clones, but to simplify the presentation the values are inverted). (b) $\log _{2}$ ratios for probes shown in panel matched on cDNA clone ID and sorted on ascending $\log _{2}$ ratio for the respective $C N$ probe. (c) Mean log2ratios for $\beta$-lactamase spikein sense (blue) and antisense (red) control features for hybridizations A to I. For individual features, log ${ }_{2}$ ratios were calculated using untransformed background corrected data (Median FG - Median BG). For mean $\log _{2}$ ratio calculations, only features where MedianFG > MedianBG in both channels, i.e. Cy3 and Cy5, and where SNR > = 3 in either channel, were included. Error bars denote +/-ISD. Mean log2ratio were calculated using values from between 66 and 70 replicated control spots. 
complementarity to the same transcript. We identified repeat sequences of 40 or more continuous bases in 358 of the 960 cDNA used for probe synthesis, 11 cases with extended self-complementarity between $\mathrm{C}$ and $\mathrm{N}$ probes and 87 cases for which the $\mathrm{C}$ and $\mathrm{N}$ probes matched the same RefSeq mRNA [20]. After filtering for potentially spurious signals, $470 \mathrm{~N}$ signals from the cell lines and 556 from the reference were interpreted as detecting putative antisense transcripts. The $\mathrm{N}$ signals detected in the cell lines vary from $27 \%$ (UACC 812 ) to $74 \%$ (CAMA-1) of the cDNAs that also showed sense transcription. We compared these signals with NATs identified by the most comprehensive study published [9]. Despite significant variations in the number of $\mathrm{N}$ signals, the percentage of detected reported NATs remains unchanged in each cell line (22.2\% on average, SD 1.2). In the reference channel, an average of $87.79 \%$ cDNAs detecting $\mathrm{C}$ signals also produced $\mathrm{N}$ signals (SD 5.65). As many as 116 putative antisense transcripts in the cell lines and 398 in the reference were detected in all nine hybridizations and, again, a similar proportion of reported antisense transcripts in each group were noted $(21.6 \%$ respectively $24.1 \%)$. We observe greater variation in the number of detected $\mathrm{N}$ signals for the cell lines compared to the reference, indicating that biological variation is larger than variation resulting from technical replication of measurements (Table 1). Here, we aimed to gain insight into the occurrence of NATs and to analyze their influence in the context of microarray hybridizations rather than to rigorously screen for novel antisense transcripts. However, $\mathrm{N}$ signals show biological variation that tend to be sample specific, yet reveal a common core detected in all experiments. This group includes genes involved in apopotosis and programmed cell death. If a significant proportion of these detected unannotated transcripts were random artifacts, we would expect the common core to show a lower proportion of known annotated transcripts. Nevertheless, it is remarkable that the proportion of annotated antisense transcripts for the common core is similar to that estimated for each cell line separately $(21.6 \%$ compared to $22.2 \%$ on average for the cell lines). To verify the nature of the detected unannotated transcripts we radio-labeled sense strands from ten randomly selected cDNAs by in vitro transcription and used them as hybridization riboprobes in Northern blot hybridizations. Seven of the ten tested riboprobes were able to identify complementary transcripts in the total RNA mixture (Fig. 3). These observations strengthen the view that most detected $\mathrm{N}$ signals might represent true NATs (either cis or trans). This impression is reinforced by the fact that hybridization with tilling arrays predicted that only one tenth of the total number of transcription units is known in human [21] and the observed well-defined expression pattern of $\mathrm{N}$ signals described subsequently. We find no reasons to conceive that this extended antisense transcriptional activ- ity is associated with the nature of the analyzed materials (mostly cancer cell lines) as MCF-10, derived from normal breast epithelia detected a number of antisense signals second closet to average. In summary, as much as $88 \%$ of the tested conventional cDNA probes could potentially produce microarray signals reflecting differences in sense or antisense expression, or both, in one sample or both of sample and reference.

\section{Relationship between $\mathbf{C}$ and $\mathbf{N}$ signals}

To analyze closely antisense expression and to explore the extent to which antisense signals might influence proteincoding profiles detected by double-stranded microarrays, we jointly investigated the relationship between signal from $\mathrm{C}, \mathrm{N}$, and $\mathrm{CN}$ probes. First, we visualized distances between expression profiles derived from separate probes using unsupervised cluster analysis. We regarded expression data from different probes as individual data sets, separating hybridizations into one $\mathrm{C}$, one $\mathrm{N}$, and one $\mathrm{CN}$ profile matched on clone IDs. Cluster analysis using probes derived from 260 cDNA clones show that $\mathrm{C}$ and $\mathrm{CN}$ profiles co-segregate within each cell line (Figure $4 \mathrm{a}$ ). The majority of $\mathrm{N}$ profiles form a cohesive cluster well separated from $\mathrm{C}$ and $\mathrm{CN}$ profiles for the same group of cell lines. For two cell lines, the N, C and CN profiles separate from all other cell lines but within each group the $\mathrm{C}$ and $\mathrm{CN}$ profiles co-segregate with the $\mathrm{N}$ profile clearly separated. Visual inspection revealed that $\mathrm{C}$ and $\mathrm{N}$ signals seem to follow coordinated variation. To corroborate this observation we calculated pair wise correlation between $\mathrm{C}$ signal and $\mathrm{N}$ signal across the nine hybridizations for corresponding cDNA clones. Figure $4 \mathrm{~b}$ shows the distribution of Pearson correlations for $430 \mathrm{C}$ and $\mathrm{N}$ signal pairs, evidencing a tendency for positive correlation between them. The same coordinated pattern was apparent when only probe pairs from cDNA clones with previously known NATs were considered. Overall, only a minority of clones showed an inverse relationship between senses and antisense expression levels. These probes seem to be responsible for the separation between $\mathrm{C}$ and $\mathrm{N}$ profiles. A tendency for positively correlated co-expression of sense and antisense transcripts has been observed in large-scale studies performed in mouse [22]. However, studies on human material claimed that expression of members of sense-antisense pairs follow an inverse relation which was supposed to agree with a mechanistic model according to which increasing expression of one of the members downregulates transcription of the other [23]. Our results contradict this observation. To verify our observation by an alternative method, we selected the gene encoding human ketohexokinase as representative example (KHK, accession number BC006233). In our microarray measurements, KHK's transcription displayed a high positive correlation between $\mathrm{N}$ and $\mathrm{C}$ signals (Pearson's correlation coefficient $r=0,97$ ). KHK exons 5, 6 and 7 fully over- 


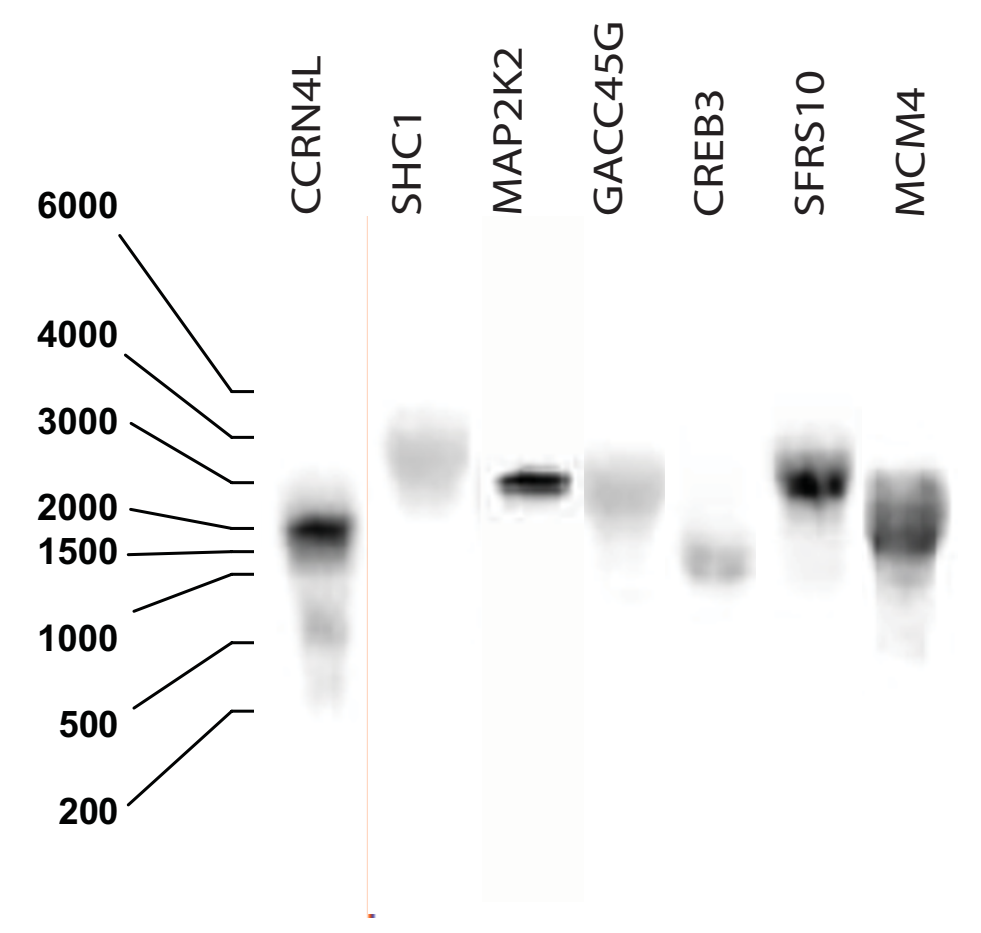

\section{Figure 3}

Validation of putative antisense RNA transcripts. Northern blot hybridizations of total RNA with sense P32-labeled riboprobes corresponding to a sample set for which antisense RNAs were detected on the single-stranded microarray but had not preciously been reported. cDNAs correspond to: ubiquitin C partial cds CCRN4L (BC000449), src homology 2 domain containing transforming protein SHCI (BC0I4I58), mitogen activated protein kinase 2 MAP2K2 (BE543096), growth arrest and DNA-damage inducible protein gamma GACC45G (BC000465), c-AMP responsive element binding protein 3 CREB3 (BCOI0I58), splicing factor SFRSIO (BC00045I) and MCM4 minichromosome maintenance deficient 4 MCM4 (BC036035).

lap clone CR623121 which transcription proceeds in the antisense orientation. We designed a forward primer on KHK exon 5 and reverse primer on exon 7 targeting the regions of sequence complementarity in both cases. Due to different splicing, this primer pair would allow simultaneous amplification of a 406 bp KHK fragment and a 626 bp product from the CR623121 transcript (Figure 4c). Figure $4 \mathrm{~d}$ shows the outcome of these RT-PCR experiments. A tight coordinated variation between expression levels of KHK and its antisense transcript was obtained across all tested cell lines $(r=0,80)$ confirming our microarray results. Thus, the analyzed genes appear to follow a pattern of more or less coordinated up- or down-regulation of both strands in parallel. Supported on previously reported data [24], we interpret the coordinated expression of $\mathrm{N}$ with $\mathrm{C}$ signals as evidence for tight sense-antisense regulation rather than the effect of a stochastic transcriptional noise. Moreover, if sense/antisense expressions tend to be correlated for protein-coding loci, we speculated that profiles should not substantially differ, regardless of whether the array probes are single- or double-stranded.

\section{Single-stranded compared to conventional double stranded cDNA arrays}

To investigate further the connection between $\mathrm{C}$ and $\mathrm{CN}$ profiles we calculated pairwise Euclidean distances between $\mathrm{C}, \mathrm{N}$ and $\mathrm{CN}$ signals across cell lines. Taken together, these data indicate that $\mathrm{C}$ and $\mathrm{CN}$ profiles are more similar across the hybridized samples than either is to $\mathrm{N}$ profiles (Figure $5 \mathrm{~b}$ ). To exclude the possibility that $\mathrm{a}$ small number of outliers caused the difference, we investigated the distribution of $\mathrm{N}$ to $\mathrm{C}$ distance per $\mathrm{CDNA}$ clone within hybridizations (5c). We found a very similar distribution for each hybridization suggesting that antisense transcription - while it is genome-wide - does not significantly distance profiles obtained from pure sense probes from those derived from dsDNA. 
Table I: Hybridization signals detected in sample channel and reference channel

\begin{tabular}{|c|c|c|c|c|c|c|c|c|c|c|c|c|}
\hline & \multicolumn{2}{|c|}{ Detected $\mathrm{N}$ signals } & \multicolumn{5}{|c|}{ Masked IMAGE ID } & \multicolumn{3}{|c|}{ Putative antisense signals } & \multicolumn{2}{|c|}{ C signals } \\
\hline & total* & $\underset{*}{\text { reported* }}$ & 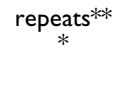 & $\begin{array}{c}\text { double } \\
\text { hits***** }\end{array}$ & $\begin{array}{c}\text { self- } \\
\text { complem } \\
\text { entarity }\end{array}$ & $\begin{array}{l}\text { repeats, } \\
\text { double, } \\
\text { or self }{ }^{++}\end{array}$ & $\underset{++}{\text { reported }^{+}}$ & total $^{++++}$ & reported $\$$ & new $\$ \$$ & total $\$ \$ \$$ & $\begin{array}{c}\text { \% paired } \\
\text { signal } \$ \$ \$ \$ \$\end{array}$ \\
\hline $\begin{array}{l}\text { UACC8I } \\
2(A)\end{array}$ & 281 & 59 & 148 & 61 & 7 & $|5|$ & 31 & 130 & $\begin{array}{c}28 \\
(21,5 \%)\end{array}$ & 102 & 353 & 27 \\
\hline $\begin{array}{l}\text { ZR7530 } \\
\text { (B) }\end{array}$ & 316 & 67 & 149 & 57 & 8 & 153 & 33 & 163 & $\begin{array}{c}34 \\
(20,9 \%)\end{array}$ & 129 & 353 & 35 \\
\hline $\begin{array}{l}\text { BT474 } \\
\text { (C) }\end{array}$ & 610 & 134 & 252 & 74 & II & 257 & 50 & 353 & $\begin{array}{c}84 \\
(23,8 \%)\end{array}$ & 269 & 478 & 64 \\
\hline $\begin{array}{l}\text { MDA36I } \\
\text { (D) }\end{array}$ & 603 & 132 & 241 & 71 & 0 & 246 & 49 & 357 & $\begin{array}{c}83 \\
(23,2 \%)\end{array}$ & 274 & 465 & 66 \\
\hline $\begin{array}{l}\text { MCFIOA } \\
\text { (E) }\end{array}$ & 556 & 114 & 241 & 72 & II & 246 & 46 & 310 & $\begin{array}{c}68 \\
(21,9 \%)\end{array}$ & 242 & 473 & 57 \\
\hline SKBR3 (F) & 449 & 94 & 192 & 65 & 8 & 196 & $4 I$ & 253 & $\begin{array}{c}53 \\
(20,9 \%)\end{array}$ & 200 & 431 & 48 \\
\hline $\begin{array}{l}\text { UACC89 } \\
3 \text { (G) }\end{array}$ & 516 & 110 & 216 & 67 & 8 & 220 & 43 & 296 & $\begin{array}{c}67 \\
(22,6 \%)\end{array}$ & 229 & 442 & 56 \\
\hline $\begin{array}{l}\text { MDA453 } \\
(\mathrm{H})\end{array}$ & 562 & 115 & 233 & 72 & 9 & 238 & 47 & 324 & $\begin{array}{c}68 \\
(21,0 \%)\end{array}$ & 256 & 460 & 60 \\
\hline $\begin{array}{l}\text { CAMAI } \\
\text { (I) }\end{array}$ & 695 & $|5|$ & 276 & 76 & II & 282 & 53 & 413 & $\begin{array}{c}98 \\
(23,7 \%)\end{array}$ & 315 & 501 & 74 \\
\hline Mean & 509,78 & 108,44 & 216,44 & 68,33 & 9,22 & 221 & 43,67 & 288,8 & $\begin{array}{c}64,78 \\
(22,2 \%)\end{array}$ & 224 & 439,56 & 54,14 \\
\hline SD & 137,63 & 30,55 & 44,89 & 6,32 & 1,56 & 45,7 & 7,53 & 92,37 & $\begin{array}{l}23,10 \\
(1,2 \%)\end{array}$ & 69,52 & 53,03 & 15,18 \\
\hline $\begin{array}{l}\text { Nmbr(uni } \\
\text { on) }\end{array}$ & 776 & 169 & 300 & 78 & II & 306 & 60 & 470 & $\begin{array}{c}109 \\
(23,2 \%)\end{array}$ & 361 & 511 & \\
\hline $\begin{array}{l}\text { Nmbr(int } \\
\text { ersection) }\end{array}$ & 244 & 52 & 125 & 55 & 7 & 128 & 27 & 116 & $\begin{array}{c}25 \\
(21,6 \%)\end{array}$ & 91 & 315 & \\
\hline $\begin{array}{l}\text { Reference } \\
\text { (A) }\end{array}$ & 753 & 169 & 296 & 78 & II & 303 & 62 & 450 & $\begin{array}{c}107 \\
(23,8 \%)\end{array}$ & 343 & 510 & 81 \\
\hline $\begin{array}{l}\text { Reference } \\
\text { (B) }\end{array}$ & 751 & 169 & 288 & 79 & II & 295 & 59 & 456 & $\begin{array}{c}110 \\
(24,1 \%)\end{array}$ & 346 & 505 & 82 \\
\hline $\begin{array}{l}\text { Reference } \\
\text { (C) }\end{array}$ & 813 & 185 & 303 & 77 & 11 & 309 & 65 & 504 & $\begin{array}{c}120 \\
(23,8 \%)\end{array}$ & 384 & 513 & 90 \\
\hline $\begin{array}{l}\text { Reference } \\
\text { (D) }\end{array}$ & 808 & 179 & 301 & 79 & II & 308 & 62 & 500 & $\begin{array}{c}117 \\
(23,4 \%)\end{array}$ & 383 & 514 & 89 \\
\hline $\begin{array}{l}\text { Reference } \\
\text { (E) }\end{array}$ & 806 & 178 & 301 & 80 & II & 307 & 62 & 499 & $\begin{array}{c}116 \\
(23,2 \%)\end{array}$ & 383 & 513 & 89 \\
\hline $\begin{array}{l}\text { Reference } \\
\text { (F) }\end{array}$ & 826 & 186 & 307 & 79 & II & 314 & 65 & 512 & $\begin{array}{c}\mathbf{I 2 |} \\
(23,6 \%)\end{array}$ & 391 & 519 & 91 \\
\hline $\begin{array}{l}\text { Reference } \\
\text { (G) }\end{array}$ & 745 & 169 & 288 & 78 & II & 294 & 62 & 451 & $\begin{array}{c}107 \\
(23,7 \%)\end{array}$ & 344 & 502 & 80 \\
\hline $\begin{array}{l}\text { Reference } \\
(\mathrm{H})\end{array}$ & 822 & 182 & 311 & 78 & 11 & 317 & 66 & 505 & $\begin{array}{c}116 \\
(23,0 \%)\end{array}$ & 389 & 520 & 90 \\
\hline $\begin{array}{l}\text { Reference } \\
\text { (I) }\end{array}$ & 874 & 196 & 316 & 79 & II & 323 & 64 & 551 & $\begin{array}{c}132 \\
(24,0 \%)\end{array}$ & 419 & 524 & 97 \\
\hline Mean & 799,78 & 179,22 & 301,22 & 78,56 & II & 307,8 & 63 & 492 & $\begin{array}{l}116,22 \\
(23,6 \%)\end{array}$ & 375,8 & 513,33 & 87,79 \\
\hline SD & 42,63 & 9,24 & 9,54 & 0,88 & 0 & 9,58 & 2,18 & 33,63 & $\begin{array}{c}7,84 \\
(0,4 \%)\end{array}$ & 26,02 & 7,07 & 5,65 \\
\hline $\begin{array}{l}\mathrm{Nmbr} \text { (uni } \\
\text { on) }\end{array}$ & 885 & 198 & 322 & 81 & II & 329 & 66 & 556 & $\begin{array}{c}132 \\
(23,7 \%)\end{array}$ & 424 & 525 & \\
\hline $\begin{array}{l}\text { Nmbr(int } \\
\text { ersection) }\end{array}$ & 673 & 153 & 269 & 75 & 11 & 275 & 57 & 398 & $\begin{array}{c}96 \\
(24,1 \%)\end{array}$ & 302 & 489 & \\
\hline \multicolumn{13}{|c|}{ 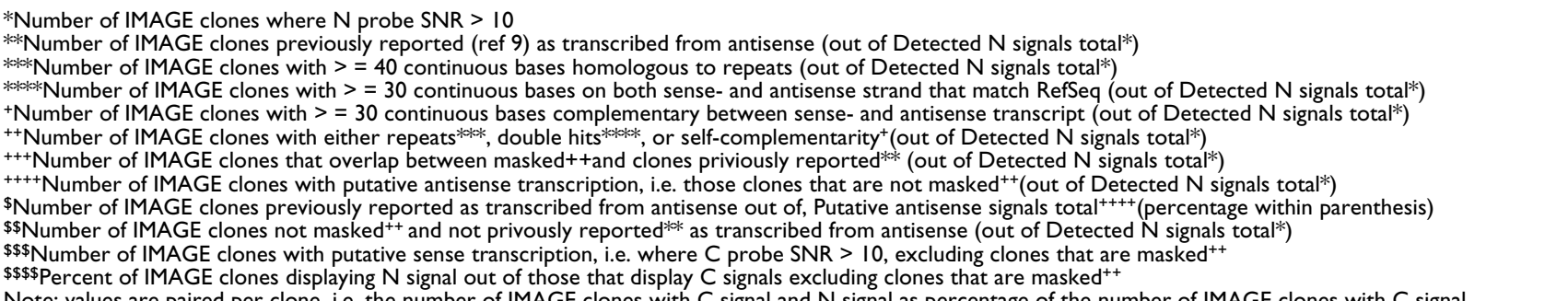 } \\
\hline
\end{tabular}




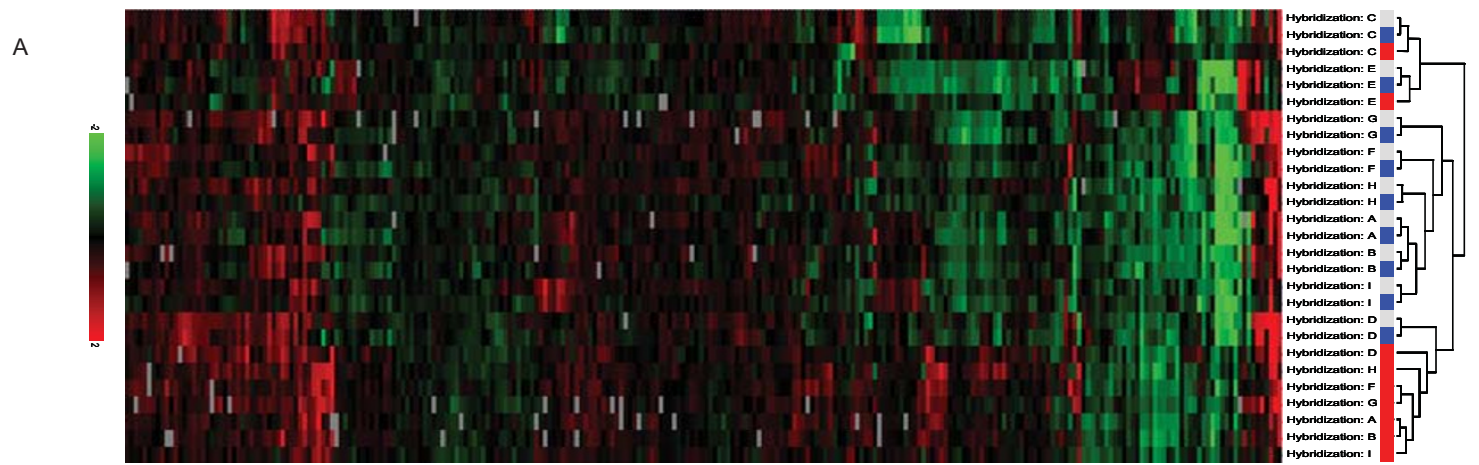

B

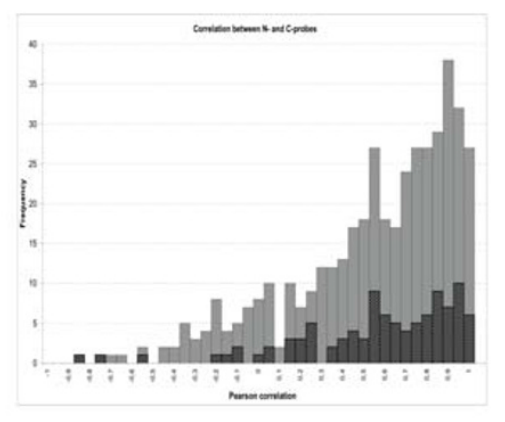

C

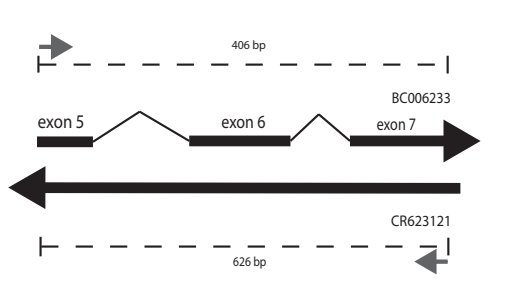

D

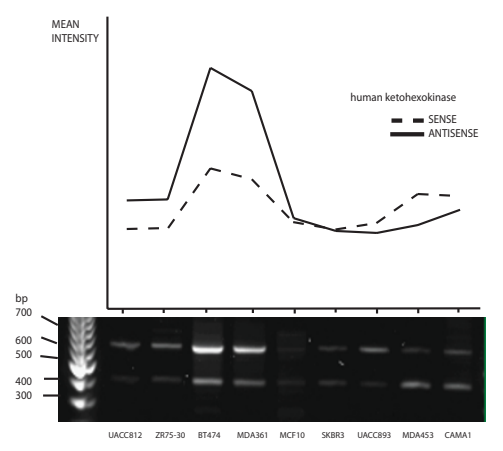

\section{Figure 4}

Sense and antisense expression profiles. (a) Unsupervised cluster analysis of expression profiles detected by $C$ (blue), $N$ (red) and CN (grey) capture probes across 9 cell lines. A: UACC8I2; B: ZR75-30; C: BT474; D: MDA36I; E MCFI0A, F: SKBR3; G: UACC893; H: MDA453 and I: CAMAI. Columns in the gene expression matrix correspond to IMAGE clone IDs. Each cell line is represented by one row. Minimum presence per cDNA clone was set to 7 out of 9 in each data set. (b) Correlation between $\mathrm{N}$ - and $\mathrm{C}$-probes across hybridizations $\mathrm{A}$ to I for 430 probe pairs, i.e. IMAGE clones. Frequency of Pearson correlation is shown as bars with a bin width of 0.05 (gray bars). For each frequency, the contribution of probe pairs from IMAGE clones previously reported as antisense transcribed is shown as striped areas. Correlation calculations are performed on log2ratios using within hybridization mean log2ratio per reporter across features with SNR $>=10$ in either channel, i.e. Cy3 or Cy5. IMAGE clones were removed if their respective $\mathrm{N}$ - and $\mathrm{C}$ - probes were suspected to potentially cross-hybridize or if their number of missing values across hybridizations was $>2$ for either $\mathrm{N}$ - or C- probe. (c) Schematic representation of the overlap between KHK (BC006233) and CR623I2I transcripts and rational of the RT-PCR reaction aimed to verify the observed coordinated regulation of sense and antisense transcripts. Black arrows represent orientation of transcription for each RNA. Grey arrows mark positions for the PCR primers used in (d). Distance between primers positions refer to the final amplification products. (d) Relative expression of KHK and its antisense CR623 I 2 I detected by RT-PCR across all cell lines. Two amplicons of 406 and 626 bp corresponding to KHK sense and antisense transcripts were obtained. Lower panel: ethidium bromide staining after separation in $1 \%$ agarose. Band intensities were quantified with the Kodak ID Image Analysis Software and mean intensities were plotted.

To test this conjecture, we treated $\mathrm{C}, \mathrm{N}$ and $\mathrm{CN}$ profiles from each cell line as part of an independent experiment. Expression data from each probe set were median-centered separately and their expression profiles compared by cluster analysis (Figure 5a). All cell lines segregate in a similar manner, independent of the nature of the probe. Moreover, the relationship between expression patterns detected by $\mathrm{C}, \mathrm{N}$ and $\mathrm{CN}$ capture probes for each one of the nine samples was similar for all of them. C and $\mathrm{CN}$ segregated consistently close to each other leaving $\mathrm{N}$ probes as outliers. We observed a closer distance between $\mathrm{C}$ and $\mathrm{CN}$ expression than between either of these profiles and $\mathrm{N}$, across all performed experiments. This could be explained by the fact that $\mathrm{N}$ probes are derived from sense transcripts cDNAs and are not a mirror copy of NATs. Therefore, mature antisense transcripts and $\mathrm{N}$ probes would not be perfectly complementary but, assuming that all sense and antisense immature transcripts undergo 
A

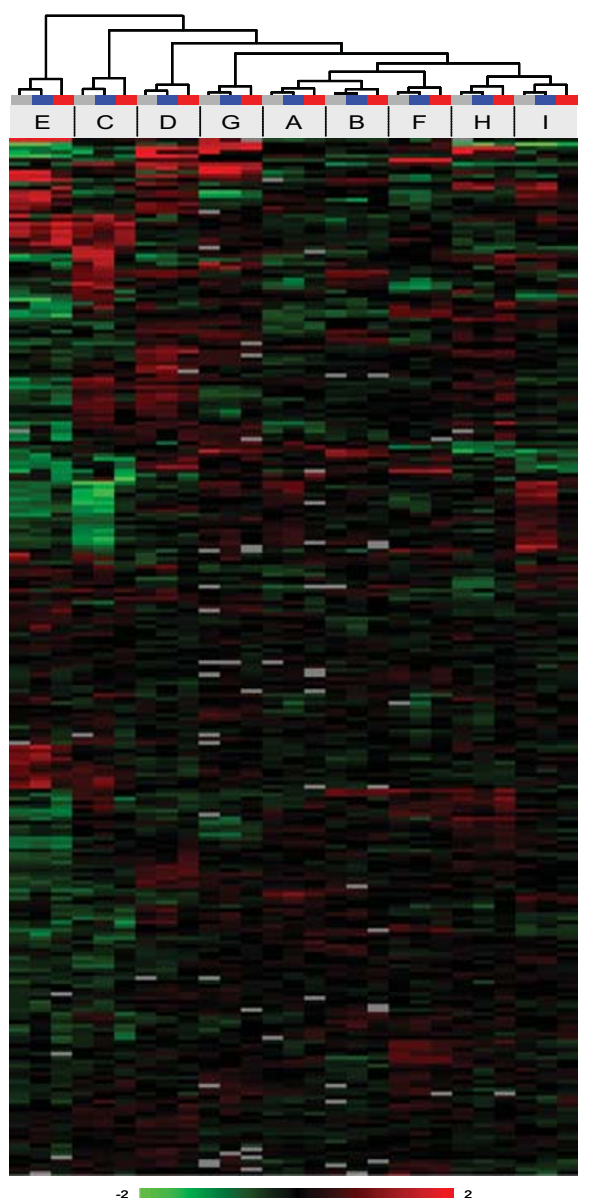

B

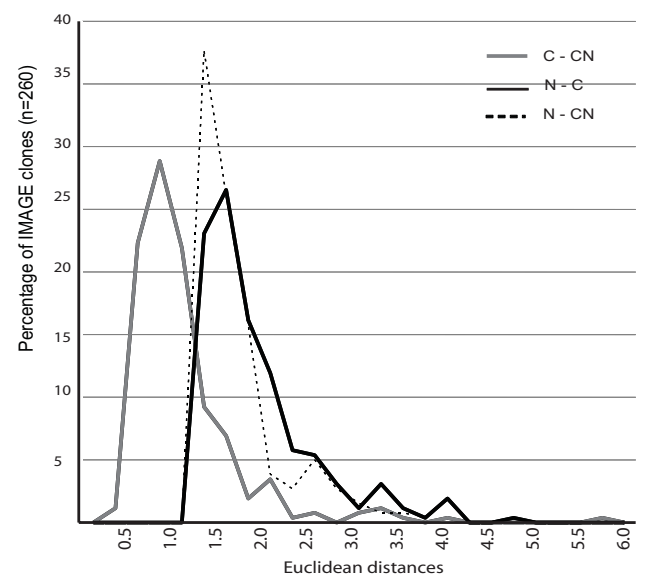

C

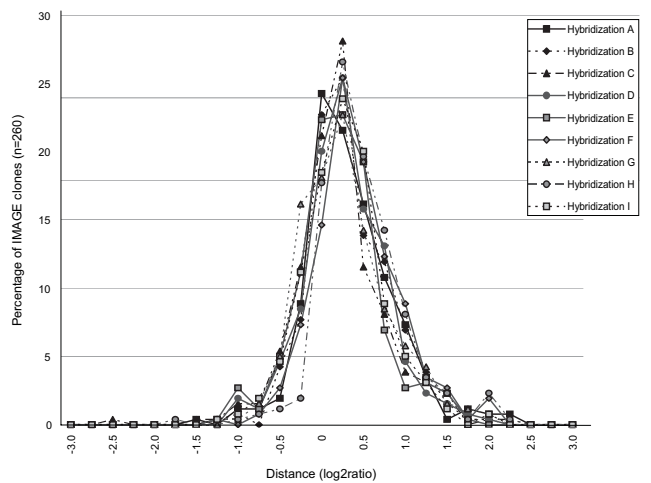

\section{Figure 5}

(a) Cluster analysis of $\mathrm{C}$ (blue), $\mathrm{N}$ (red) and $\mathrm{CN}$ (grey) expression profiles where all samples were median-centred and treated as they were independent experiments. Minimum presence per cDNA clone was set to 7 out of 9 in each data set. (b) Histogram of pair-wise Euclidean distances over all samples for IMAGE clones. For each IMAGE in 9 dimensions, i.e. hybridization I9, the Euclidean distance between $C$ and $N$ is $\sqrt{ }\left(\sum i=I\left(C_{i}-N_{i}\right)^{2}\right)$ where $C_{i}$ and $N_{i}$ is the log2ratio for $C$ and $N$ probe respectively for hybridization i. (c) Histogram of distances between $\mathrm{C}$ and $\mathrm{N}$ probes for all IMAGE for each hybridization.

splicing, will display restricted regions of exon overlap. This situation should favor the hybridization dynamics of $\mathrm{C}$ probes since renaturation kinetic is directly dependent on the length of the complementarity with the immobilized probes [25].

\section{Conclusion}

In spite of stringent signal-to-noise ratio criteria, our strand-specific cDNA microarrays detected a number of antisense transcripts that exceeds by far the number of previously annotated antisense genes in humans. Partial validation and observed well defined expression patterns suggest that a considerable fraction of these signals might represent bona-fide unannotated antisense transcripts (both cis- and trans). These NATs are expressed in a cell specific manner and displayed a strong tendency to follow the expression pattern of their sense counterparts.

Since antisense transcription data is embedded in double stranded cDNA array experiments, it is expected to affect signals and gene clusters, and would make data validation difficult of array results by other means. We analyzed this 
issue and found that even if antisense transcription is genome-wide it exerts a restricted influence on the interpretation of conventional cDNA microarray data. Today, these problems can be circumvented in well-annotated genomes because strand specific expression can be discriminated by the use of oligonucleotide capture probes. However, strand-specific oligo design would be hampered today by the limited access to antisense sequence data, as shown here. Although reassuring the overall validity of cDNA microarrays in previous tumour-classification studies, our results emphasize the need for further development of methods that accurately measure strand-specific expression.

\section{Methods}

\section{Preparation of capture probes}

To produce cDNA arrays, 960 full-length cDNA clone inserts from the MGC collection [15] (plates IRAT3, IRAT33, IRAU2, IRAU19, IRAU31, IRAU44, IRAU46, IRAU62, IRAU68 and IRAU71) were amplified three times using different combinations of 5'-amino modified M13 universal sequencing primers (GTTGTAAAACGACGGCCAGTG forward and CACACAGGAAACAGCTATG reverse). One reaction set used 5'-amino C-6 link modified M13 forward paired with a non-modified reverse primer. A second reaction used 5'-amino C-6 link modified M13 reverse primer paired with a non-modified forward primer. A third reaction used 5'-amino C-6 link modified primers in both orientations to produce doublestranded probes. Amino-modified M13 forward primers were used to produce sense (coding) strand probes and M13 reverse primers to produce non-coding antisense strand probes in all reactions except those corresponding to plate IRAU3 (cloned into pCMV-SPORT6 with the cloning site in opposite orientation). To produce capture probes for the test array used in Figure 1, a one kilo-base (kb) fragment from the $\beta$-lactamase gene was amplified using the same procedure but with plasmid DNA as template and primers GGCACCTATCTCAGCGATCT and GCGGAACCCCTATTTGTTTA.

After amplification, all PCR products were precipitated with ethanol and resuspended in phosphate buffer at approximately $100 \mathrm{ng} / \mu \mathrm{l}$ for further deposition on arrays. Triplicates of sense and antisense amino-modified $\beta$-lactamase PCR products were also deposited on each of the blocks of the CDNA array to monitor the processing of double-stranded DNA to single-stranded (ssDNA).

Amino-modified PCR products were spotted onto CodeLink activated slides (Amersham) using a MicroGrid II array robot (BioRobotics). Capture probes on slides used in Figure 1 were printed as $10 \times 10$ replicates. The test slides also included background control spots produced by processing PCR reactions without template (PCR primers with no amplification product).

After printing, slides were coupled in a saturated $\mathrm{NaCl}$ chamber overnight at room temperature, blocked in 50 mM ethanolamine, $0,1 \mathrm{MTris}(\mathrm{pH}$ ) $)$ at $50^{\circ} \mathrm{C} 30 \mathrm{~min}$ followed by washes in distilled water and $4 \times$ SSC/0.1\% SDS at $50^{\circ} \mathrm{C}$. The deposited dsDNA was subsequently digested in situ with T7 exonucelase 6 . Slides were overlaid with 45 $\mu \mathrm{l}$ exonuclease reaction mixture $(1 \mathrm{U} / \mu \mathrm{l} \mathrm{T} 7$ exonuclease 6 in $1 \times$ reaction buffer, New England Biolabs), covered with a coverslip and left to incubate for 30 minutes at $25^{\circ} \mathrm{C}$ in a CMT Corning hybridization chamber. Following in situ digestion, probes were denatured by immersing the arrays in boiling water for two minutes.

\section{Microarray hybridization}

To produce targets for hybridization of the test array shown in Figure 1, the T7 RNA polymerase promoter was incorporated by PCR in the sense or antisense orientation relative to the $\beta$-lactamase gene, and corresponding transcripts were synthesized by in vitro transcription. For the cDNA arrays, total RNAs were extracted from cell lines ZR75-30, BT-474, SKBR-3, MDA-361, UACC-812, UACC893, CAMA1, MDA453 and MCF-10 with Trizol (Invitrogen), purified with Qiaex (Qiagen), and integrity was checked on a Bioanalyzer (Agilent). Targets of in vitro transcribed $\beta$-lactamase, total RNA from cell lines, or Human Reference RNA (Stratagene) were direct labeled by random priming (Promega, Pronto). Spike-in controls were included together with the cell line hybridization mixtures. A $1 \mathrm{ng}$ spike-in of 5' amino-modified 50-mer DNA oligos with sequence complementarity to either the sense or antisense strand of the $\beta$-lactamase fragment were incubated in $0.3 \mathrm{M}$ hydroxylamine at room temperature with monofunctional Cynine5 or Cynine3 reactive dyes (Amersham). The labeled long-mers were mixed in each breast cell line targets (Cy3 label) or Human Reference RNA (Cy5 label). A similar labeling method was used for the M13 forward and M13 universal sequencing primers used to validate the single stranded nature of the array (Figure 2a-b). All hybridizations were performed in $4 \times$ SSC, $0.1 \%$ SDS, with human $0.5 \mu \mathrm{g} / \mu \mathrm{l} \mathrm{Cot}-1$ DNA at $42^{\circ} \mathrm{C}$ overnight. Washes following hybridization were three times $4 \times$ SSC RT, twice $2 \times$ SSC/0.1\% SDS at hybridization temperature, one time $0.2 \times$ SSC and finally one time $0.1 \times$ SSC RT. Slides were dried by centrifugation and scanned.

Identification of potential non-specific cross-hybridization Sequence information for the MGC clone inserts was retrieved from the MGC home page [16]. Repeat sequences were identified using RepeatMasker (A.F.A. Smit, R. Hubley \& P. Green, unpublished data). Clone inserts with repeats for which the product of repeat length 
and similarity to the consensus sequence [ 1 - divergence] was greater than 40 were identified as repeat containing. Self-complementarity of strands was identified by aligning the reverse complement of the clone insert sequence against itself (NCBI blast; word size $=7$, e-value cut-off $=$ $1000)$. Sequences with self-complementary matches of 30 basepairs or more ( $>79 \%$ identity) were identified as selfcomplementary. Clone insert sequences and their reverse complement for all cDNAs were also aligned against the RefSeq mRNA database to identify sequences for which both the sense and antisense matched the same RefSeq mRNA over at least 30 basepairs with $>80 \%$ identity (NCBI blast, word size $=7$, e-value cut-off $=1000$ ).

\section{Data analysis}

Hybridized arrays were scanned using an Axon 4000A scanner (Axon Instruments). Acquired TIFF images were analyzed and individual spots were flagged as not found, found, or bad, in GenePix Pro 4 (Axon Instruments). The quantified data matrix was saved as a GenePix Results File (gpr) and loaded into a local installation of BioArray Software Environment (BASE) [17]. Subsequent pre-processing steps, within slide normalization, data filtration, and transformations were performed with in BASE. Median foreground pixel intensities for spots were adjusted by subtracting median background pixel intensities. Spots flagged as not found or bad during image analysis or considered saturated (containing more than 5\% saturated pixels in either signal) were removed. Data within arrays were normalized to the median $\log 2$ ratio of sample intensity to reference intensity. Median $\log 2$ ratio was calculated using spots with both signal intensities above 100 and excluding the 5\% highest and 5\% lowest log2 ratios. Spots with both signal-to-noise levels below 10 were removed and replicated spots were merged. Hierarchical cluster analysis was performed using $\mathrm{TMeV}$ [18].

\section{Northern blot hybridization and RT-PCR validation experiments}

For northern blots, $25 \mu \mathrm{g}$ total Human Reference RNA (Stratagene) were loaded on 1,3\% agarose gels containing formaldehyde. RNA Ladder High Range (Fermentas Life Sciences) was used as molecular weight standard. Electrophoresis was run in $1 \times$ MOPS. The separated RNAs were transferred onto Hybond $\mathrm{N}+$ nylon membrane by capillarity and subsequenlty cross-linked under UV light. P32 radiolabelled strand specific probes were synthesized by in vitro transcription (Riboprobe System, Promega). Hybridizations were performed in $50 \%(\mathrm{v} / \mathrm{v})$ formamide, $5 \times$ SSPE, $5 \times$ Dendhardt's, 0,5\% SDS, $100 \mu \mathrm{g} / \mathrm{ml}$ boiled salmon sperm DNA at $42^{\circ} \mathrm{C}$ overnight. The blots were subsequently washed 3 times in $2 \times$ SSC:0,1\%SDS RT and twice $10 \mathrm{~min}$ in $0,1 \times \mathrm{SSC}: 0,1 \% \mathrm{SDS}$ at $65^{\circ} \mathrm{C}$.
For RT-PCR, first strand cDNAs from each cell line were prepared from $500 \mathrm{ng}$ total RNA. In all cases, reverse transcription was primed with a mixture of random hexamers using the Transcriptor First Strand cDNA Synthesis Kit (Roche Applied Sciences). One twentieth of the cDNA synthesis reaction was used as template in each PCR reaction. PCR reactions were primed with BC006233_for 5' TGTTTGTCAGCAAAGATGTGG and BC006233_rev 5' CTGGATGGAGGGGAGAAG. Expand High Fidelity polymerase (Roche Applied Sciences) was used for all reactions. Cycling conditions were: $2 \mathrm{~min}$ at $94^{\circ} \mathrm{C}, 20 \mathrm{sec}$ onds at $94^{\circ} \mathrm{C}, 30$ seconds at $55^{\circ} \mathrm{C}, 2$ minutes at $72^{\circ} \mathrm{C}$ and extension final of 10 minutes at $72^{\circ} \mathrm{C}$. PCR products were resolved in $1 \%$ agarose gel electrophoresis and band intensities were measured with a Kodak 1D Image Analysis Software system.

\section{Authors' contributions}

JVC performed the studies, microarray analysis and participated in the draft of the manuscript. JS constructed the microarrays and participated in the design of the study. $\mathrm{AK}$ and PM carried out the bioinformatic analysis and participated in revision of manuscript. $\AA \mathrm{B}$ participated in the design of the study. CR drafted the manuscript and conceived, designed and coordinated the study.

\section{All authors read and approved the final manuscript.}

\section{Acknowledgements}

We thank Amilcar Flores, for old fruitful discussions, Jessica Ahlsiö for skilled technical assistance, Carsten Peterson, Mattias Höglund and Timothy Hemesath, for their comments on the manuscript.

This work was supported by grants from the The Royal Physiographic Society in Lund, Erik Philip-Sörensen Foundation, Berta Kamprad Foundation, SWEGENE, American Cancer Society, and the Swedish Cancer Society.

\section{References}

I. Storz G: An expanding universe of noncoding RNAs. Science 2002, 296:1260-1263.

2. Pang KC, Stephen S, Engstrom PG, Tajul-Arifin K, Chen W, Wahlestedt C, Lenhard B, Hayashizaki Y, Mattick JS: RNAdb - a comprehensive mammalian noncoding RNA database. Nucleic Acids Res 2005, 33:DI25-DI30.

3. Huttenhofer A, Schattner P, Polacek N: Non-coding RNAs: hope or hype? Trends Genet 2005, 2 1:289-297.

4. Lavorgna G, Dahary D, Lehner B, Sorek R, Sanderson CM, Casari G: In search of antisense. Trends Biochem Sci 2004, 29:88-94.

5. Lehner B, Williams G, Campbell RD, Sanderson CM: Antisense transcripts in the human genome. Trends Genet 2002, 18:63-65.

6. Shendure J, Church GM: Computational discovery of senseantisense transcription in the human and mouse genomes. Genome Biol 2002, 3:research 0044.

7. Yelin R, Dahary D, Sorek R, Levanon EY, Goldstein O, Shoshan A, Diber A, Biton S, Tamir Y, Khosravi R, et al.: Widespread occurrence of antisense transcription in the human genome. Nat Biotech 2003, $21: 379-386$.

8. Chen J, Sun M, Kent WJ, Huang X, Xie H, Wang W, Zhou G, Shi RZ, Rowley JD: Over $\mathbf{2 0 \%}$ of human transcripts might form senseantisense pairs. Nucleic Acids Res 2004, 32:48I 2-4820.

9. Engström PG, Suzuki H, Ninomiya N, Akalin A, Sessa L, et al:: Complex Loci in Human and Mouse Genomes. PLoS Genetics 2006, 2:e47. doi:10.1371/journal.pgen.0020047 
10. Kiyosawa H, Mise N, Iwase S, Hayashizaki Y, Abe K: Disclosing hidden transcripts: mouse natural sense-antisense transcripts tend to be poly(A) negative and nuclear localized. Genome Res 2005, I 5:463-474.

II. Perou CM, Sorlie T, Eisen MB, van de Rijn M, Jeffrey SS, Rees CA, Pollack JR, Ross DT, Johnsen H, Akslen LA, et al.: Molecular portraits of human breast tumours. Nature 2000, 406:747-752.

12. Rhodius $V$, LaRossa $R$ : Uses and pitfalls of microarrays for studying transcriptional regulation. Curr Opin Microbiol 2003, 6:114-119.

13. Carninci P, Kasukawa T, Katayama S, Gough J, Frith MC, Maeda N, Oyama R, Ravasi T, Lenhard B, Wells C, et al:: The transcriptional landscape of the mammalian genome. Science 2005, 309:1559-1563.

14. Larkin JE, Frank BC, Gavras H, Sultana R, Quackenbush J: Independence and reproducibility across microarray platforms. Nat Methods 2005, 5:337-344.

15. Strausberg RL, Feingold EA, Grouse LH, Derge JG, Klausner RD, Collins FS, Wagner L, Shenmen CM, Schuler GD, Altschul SF, et al.: Generation and initial analysis of more than 15,000 full-length human and mouse cDNA sequences. Proc Natl Acad Sci USA 2002, 99:16899-16903.

16. [http://mgc.nci.nih.gov/].

17. Saal LH, Troein C, Vallon-Christersson J, Gruvberger S, Borg A, Peterson C: BioArray Software Environment (BASE): a platform forcomprehensive management and analysis of microarray data. Genome Biol 2002, 3:SOFTWARE0003.

18. Saeed Al, Sharov V, White J, Li J, Liang W, Bhagabati N, Braisted J, Klapa M, Currier T, Thiagarajan M, et al.: TM4: a free, open-source system for microarray data management and analysis. Biotechniques 2003, 34:374-378.

19. Medstrand P, van de Lagemaat LN, Mager DL: Retroelement distributions in the human genome: variations associated with age and proximity to genes. Genome Res 2002, I 2: | 483- I 495.

20. Pruitt KD, Tatusova T, Maglott DR: NCBI Reference Sequence (RefSeq): a curated non-redundant sequence database of genomes, transcripts and proteins. Nucleic Acids Res 2005, 33:D50I-D504.

21. Cheng J, Kapranov P, Drenkow J, Dike S, Brubaker S, Patel S, Long J, Stern D, Tammana H, Helt G, et al:: Transcriptional maps of 10 human chromosomes at 5-nucleotide resolution. Science 2005, 308: I| |49-II54

22. Katayama S, Tomaru Y, Kasukawa T, Waki K, Nakanishi M, Nakamura M, Nishida H, Yap CC, Suzuki M, Kawai J, et al:: Antisense transcription in the mammalian transcriptome. Science 2005 309:1564-6.

23. Chen J, Sun M, Hurst LD, Carmichael GG, Rowley JD: Genomewide analysis of coordinate expression and evolution of human cis-encoded sense-antisense transcripts. Trends Genet 2005, 21:326-329.

24. Cawley S, Bekiranov S, Ng HH, Kapranov P, Sekinger EA, Kampa D, Piccolboni A, Sementchenko V, Cheng J, Williams AJ, et al.: Unbiased mapping of transcription factor binding sites along human chromosomes $2 \mathrm{I}$ and 22 points to widespread regulation of noncoding RNAs. Cell 2004, I 1 6:499-509.

25. Stillman BA, Tonkinson JL: Expression microarray hybridization kinetics depend on length of the immobilized DNA but are independent of immobilization substrate. Anal Biochem 200I, 295: $149-157$.
Publish with Biomed Central and every scientist can read your work free of charge

"BioMed Central will be the most significant development for disseminating the results of biomedical research in our lifetime. "

Sir Paul Nurse, Cancer Research UK

Your research papers will be:

- available free of charge to the entire biomedical community

- peer reviewed and published immediately upon acceptance

- cited in PubMed and archived on PubMed Central

- yours - you keep the copyright
BioMedcentral 